\title{
On the monitoring of structures and soils by tomography
}

\author{
R. Zinno \& F. Magarò \\ Department of Computer Science, Modeling, Electronics and \\ Systems Engineering, University of Calabria, Italy
}

\begin{abstract}
Since 2009, with the coming into force of the January 14, 2008 Ministerial Decree "New technical standards for construction", and the explanatory ministerial communication $\mathrm{N}^{\circ} .617$ of February 2, 2009, the question of seismic hazard and the design of seismic-resistant structures in Italy has acquired increasing importance. One of the most discussed aspects in recent Italian and international scientific literature concerns the dynamic interaction between land and structure, and the effects which dynamic coupling may have on individual buildings. In effect, from systems dynamics, it is well known that resonance can have catastrophic effects on a stimulated system, leading to a response that is not compatible with the previsions in the design phase. The method used in this study to estimate the frequency of oscillation of the structure involves the analysis of HVSR (Horizontal to Vertical Spectral Ratio) relations. This allows for evaluation of very simple oscillation frequencies for land and structures. The tool used for data acquisition is an experimental digital tomograph. This is an engineered development of the experimental Languamply RE 4500 tomograph, equipped with an engineered amplification circuit and improved electronically using extremely small electronic components (the size of each individual amplifier is $16 \times 26 \mathrm{~mm}$ ). This tomograph is a modular system, which is completely "free" and "open", designed to interface Windows, Linux, OSX and Android with the outside world. It an amplifier designed to carry out microtremor measurements, yet which will also be useful for seismological and seismic measurements in general. The development of single amplifiers of small dimension allows for a very clean signal since being able to position it a few centimetres from the geophone eliminates cable "antenna" phenomena, which is a necessary characteristic in seeking to have signals which are clean at the very low voltages to be measured.

Keywords: HVSR technique; seismic hazard; resonance frequency, Southern Italy.
\end{abstract}




\section{Introduction}

The trend of the velocity of propagation of shear waves in the first subsurface (profile of Vs) is, in general, important information for the mechanical characterization (in the dynamic field) of land. In particular, it is fundamental in studies of local seismic response. As a result of an earthquake, it is often possible to observe how the damage distribution in the affected area is highly heterogeneous and in equal proportion to the vulnerability of buildings. The geological engineering conditions of the upper layers and the geomorphological characteristics may contribute, in fact, to increase locally the shaking caused by an earthquake. For effective prevention, in the field of seismic risk, it is therefore necessary to take into account not only the national seismic zonation, but also any unfavorable local conditions, within individual communes.

Particularly relevant are the so-called amplification effects of the site, namely the set of changes in amplitude, duration and frequency content of a seismic motion [1], with respect to a rock formation base, manifesting themselves through the overlying layers, up to the surface. These effects are caused, primarily, by a process of entrapment and resonance of the energy of the earthquake within a volume of subsoil consisting of sedimentary materials at a low level of seismic impedance (IS: product of the wave propagation speed by the density of the medium) and placed on a domain with a higher IS, for example a bedrock or soil which is particularly rigid.

During propagation from the source to the site, the seismic radius, due to the refraction phenomenon, undergoes a process of verticalisation and tends to emerge along a sub-vertical direction, compressional waves (P). However, it is the horizontal force due to shear waves $(\mathrm{S})$, which is the main cause of damage to buildings. Buildings and architecture in general are tested to withstand heavy static loads but the response to dynamic horizontal forces is almost never evaluated. From the above, it follows that study of the mode of propagation and amplification of transverse or shear (S) waves in the subsoil implies forecasting, at low cost, the stresses that a structure must withstand during the occurrence of a probable seismic event. Among the methods that calculate the Vs profile of the subsoil, particular interest is being devoted to those defined as of a "passive" type or based on the study of continuous vibration of the soil due to both anthropogenic and natural causes (environmental vibrations) [2].

These techniques allow the measurement of the speed of propagation of seismic waves already present in the soil due to natural sources (for example, wind and storms) or those man-made (for example, city traffic and industrial activity). With the same characteristics of seismic stringings and sensors, the methods of "passive" type reach depths of exploration far superior to any other seismic technique. The most common "active", techniques in fact, (such as refraction and reflection) are not able to investigate ground thickness at more than a few dozen meters [3]. The above depends on the fact that this type of investigation records the speed of propagation of signals generated by sources controlled artificially and at low energy (a blow of a hammer, for example) which do not ensure a penetration 
of the waves in the subsurface so as to justify exploration deeper than that previously indicated.

On the other hand, "passive" methodologies, exploiting significant energy sources (sea waves, for example), in addition to being characterized by exploration depth to the order of hundreds of meters, are particularly suitable for application in urban areas, because they exploit that portion of the signal that the other geophysical methods discard, and which rarely suffer a low ratio between signal and noise [4]. If on the one hand, therefore, "passive" techniques demonstrate numerous advantages of application, on the other, the fact that the sources are not known and controlled leads to a lower accuracy of the measurements which result in considerable ambiguity in processing data [5]. Recordings of environmental vibrations are often characterized by a considerable degree of uncertainty and prove effective when they are partly preceded by some knowledge of the lithologies under examination that permits elimination of those results which are most unlikely. In this context, however, these methods are very powerful because they allow applications to characterize, quickly and relatively cheaply, not only large thicknesses of soil but also extensive areas on the map [6].

The model proposed [7] for the rapid assessment of the dynamic behaviour of a building is based on the direct relief of asynchronous single-station measures and on the joint determination of the properties of the soil and the foundation of the structure, separating the effects of the one and the other by the use of a digital tridirectional type TROMINO tomograph. The tomograph is a particular data acquisition instrument with relatively low sampling frequency $(80-300 \mathrm{~Hz}$ ) capable of recording for a relatively long time (10-30 minutes). Data are acquired by the three channels connected to the geophones arranged according to the axes $\mathrm{X}, \mathrm{Y}, \mathrm{Z}$ and recorded on a magnetic and/or SD and/or transmitted in real time as data to a PC [8].

\section{General outline of the geological characteristics of the Longobucco area}

The survey aims to define the geology, stratigraphic sequence, the morphological characteristics and hydrology of the area directly under scrutiny in the project and a larger area, extensive enough to determine the situation and geomorphology of the catchment area of the River Trionto, so as to provide guidance to the correct sizing of all the works related to the project mentioned above.

Surveys and investigations on the ground, together with the bibliographical information acquired, deduced from the consultation of the Geological Map of Italy - 1: 25.000 - (Cape Trionto and Calopezzati) made it possible to define the geological situation of the area and the geomorphological features of the site in question.

Identification of the geological characteristics were used to define the stratigraphy of the land in the area investigated. In effect, the individual lithological units are identified, as well as the methods and age of their emplacement, and the geometric relationships and the hydrological characteristics defined. 
The Trionto is a river in Calabria that originates in the Sila mountain range, in the province of Cosenza, and flows eastward until it reaches the Ionian Sea after a distance of about $40 \mathrm{~km}$.

The basin is in a West to East direction in the mountainous part, in a SouthWest to North-Easterly direction in the middle part, and, finally, in a South-West to North-Easterly direction in the valley section until it reaches its delta in a South to North direction and in the direction SN, with a characteristic fan-shape, curve and expanded, with the apex pointing downstream [9]. The lithologies outcropping in the mountainous part of the catchment area are attributable to the igneousmetamorphic Paleozoic complex.

From bottom to top, the sedimentary series is composed of:

$>$ quartz conglomerates and quartzarenites, lithoarenites, cement quartz sandstone with interbedded red pelitic Decimetre. Limestone, dark grey loops upwards to finer grained very powerful limestone, well-laminated with decimetric layers;

> Marne, grey marly limestone with interbedded litoareniti and lentiform conglomeratic bodies passing locally to red breaches and stratified sandstone;

> Quarzoarenites, litharenites mudstone and limestone alternating with conglomeratic bodies and lentiform sandstone;

$>$ Limestone marl thinly laminated with interbedded centimetric pelitics and rare thin interbedded graded sandstone;

$>$ Alternating graded sandstone (quarzoarenites, calcarenites and lithoarenites) and mudstone with conglomeratic levels, in continuity with the underlying limestone, well stratified in layers of 30 and $60 \mathrm{~cm}$.

\section{Measuring technique and instrumentation}

The HVSR (Horizontal to Vertical Spectral Ratio) technique involves direct measurement, using the background environmental sound (microtremor), the resonance frequencies of the buildings and of the land making up the ground, in order to estimate the site effects and the seismic vulnerability of the structure. Background environmental sound comprises all vibrations [10] propagated in the soil due to both natural phenomena, waves, storms, etc., and human action, vehicular traffic, machinery, and so on. It has been recognized, from the early studies by Kanai (1957) onwards, that several methods have been proposed to obtain information, also on the subsurface, from seismic noise recorded at a site [11]. Among these, the technique that is more consolidated in use is that of the relationship between the spectral components of the horizontal motion and the vertical (Horizontal to Vertical Spectral Ratio, HVSR or H/V), proposed by Nogoshi and Igarashi [13]. This technique is widely recognized as effective in providing reliable estimates of the fundamental resonance frequency of the subsurface [12].

In practice, what is being measured in a certain range of frequencies, usually $0.1-100 \mathrm{~Hz}$, is the speed of the microtremors along the horizontal and vertical plane $(\mathrm{H}$ and $\mathrm{V})$ and the ratio between the two components $(\mathrm{H} / \mathrm{V})[14]$. 
The values of local maximum (positive peaks) of the $\mathrm{H} / \mathrm{V}$ which correspond to the local minima of $\mathrm{V}$ identify the resonance frequencies of the soil layers along the vertical measurement. The higher the value of the $\mathrm{H} / \mathrm{V}$ ratio, the greater the contrast of seismic impedance and therefore the speed variation of S-waves between contiguous stratigraphic levels [15].

The HVSR technique requires the use of a triaxial velocimeter, i.e. of a single station seismometer which can record microtremors along the two horizontal directions $(\mathrm{X}, \mathrm{Y})$ and along the vertical $(\mathrm{Z})$, fora wide range of frequencies $(0.1-$ $100 \mathrm{~Hz}$ ) and for a sufficiently long duration (an average of 10-20 minutes). The motion induced in the ground is measured [16] in terms of speed through three velocimeters, one for each direction of measurement (X, Y, and Z), according to the sampling step set by the operator. The recorded measurements are then processed and returned graphically in the form of spectra $\mathrm{H} / \mathrm{V}(\mathrm{H} / \mathrm{V}$ ratio as a function of frequency, where $\mathrm{H}$ is the average of the measurements along the $\mathrm{X}$ and $\mathrm{Y}$ ) and $\mathrm{V}$ spectra (Vertical component of the motion as a function of frequency). Through the HVSR technique you can:

- Evaluate quantitatively the effects of the site (local seismic response and susceptibility to liquefaction of the ground);

- Obtain the profile of the S-wave velocity with depth and calculate the Vs30 parameter;

- Analyze the seismic vulnerability of the buildings; either existing or planned.

With this technique, we measured the seismic noise of a bridge road for the purposes of effecting structural monitoring. The data acquired were compared with accelerometer measurements. The instrument used for this measurement of seismic noise is an experimental tomograph (Fig. 1), using the single-station method. It consists of:

free acquisition software - opensource;

hardware design - opensource (free online).

The hardware:

adconverter + three preamps + three velocimetric transducers (geophones)

Specifications are:

3 channels (can connect from 1 to 24 and over);

Sampling frequency of 500 samples second channel also with 24 channels;

Noise 0.17 microvolts;

Band pass filter of $0.25 \mathrm{~Hz} 80 \mathrm{~Hz}$;

Duration acquisition limited by ram pc (hours);

Gain $10000 \mathrm{x}$ editable with additional resistance.

Display of real-time signal

Time sampling settable 2, 3, 4, 5, 6, 7, 8, 9, 10, 15, 20, 25, 50, 100 milliseconds and intermediate values;

Single acquisition in duration at channel-to-channel frequency;

Opportunity to acquire each channel with different sample rate;

Practically simultaneous acquisition for all channels;

Display of real-time signal. 


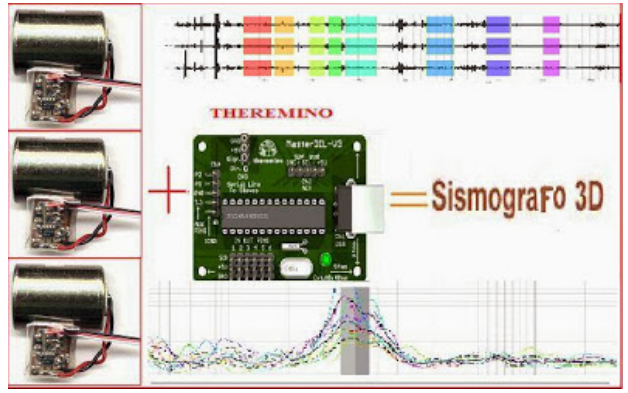

Figure 1: Schematic experimental tomograph.

A vibration transducer is essentially constituted of a sensor for detecting the vibration, an amplifier and an indicator or recorder. In particular, a sensor is a measuring system that converts a physical quantity into electronic magnitude with an analogue or digital output. Depending on the nature of the sensors, there are different types of transducers. For example, those that measure relative accelerations are known as accelerometers. These are the measuring instruments most used in modal analysis, on account of their small size and because other sizes (displacements and speed) can be obtained with simple integration procedures. Their use is particularly indicated in those tests where the excitement is of environmental type, although in recent years there has been an increase in the employment of applications involving the use of geophones. The accelerometer can be defined as an electronic sensor able to detect acceleration on different perpendicular axes $\mathrm{x}, \mathrm{y}, \mathrm{z}$ returning a signal proportional to the acceleration. It has a small vibrating mass-spring system which, undergoing a shift of its casing, connected to the structure, starts to oscillate.

\section{Data analysis}

The bridge studied is located in the municipality of Longobucco (Cs). Overlooking the long Trionto River gorge, it has a span of about 90 meters and is about 15 meters in height. It is an arched bridge, designed by the engineering firm of Prof. Ing. Luigi Naccarato, and dates back to 1968. The execution of the work was carried out by Ugo Coia Company.

The bridge, completely constructed of reinforced concrete, consists of a central part, in correspondence to the arc, of 55.80 meters, and three-sides, one of which is 10 meters on the right hand side and two are 12 meters on the left hand side (Fig. 2). The structure is then formed by two shoulders and 12 and septa, on which the four main girders are placed at intervals of $1.90 \mathrm{~m}$, and on which in turn is built the constructed base that houses the roadway. The latter also consists of a jump of $0.80 \mathrm{~m}$ in correspondence of which a sidewalk was made with a height of $0.20 \mathrm{~m}$. There are only two discontinuous joints in the road surface, placed in correspondence to the septa end of the arc. The main beams are also connected by crossbeams, placed with a typical step of $6 \mathrm{~m}$, in order to increase the torsional stiffness of the floor. 


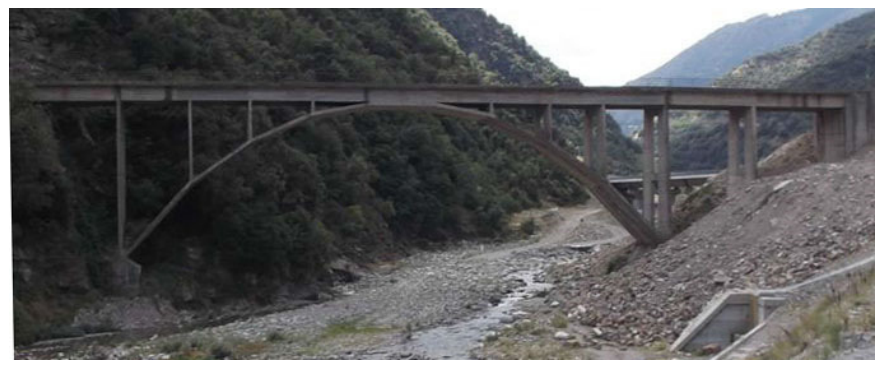

Longitudinal section

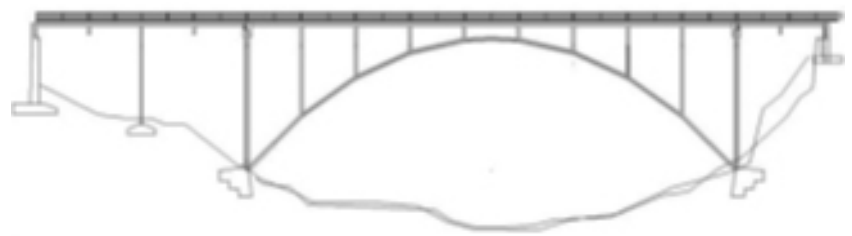

Figure 2: Photos and scheme arch bridge - Longobucco, Cosenza, South Italy.

The graph shows two main frequencies, one at $2.75 \mathrm{~Hz}$ with amplitude approximately 3.5 or $5.5 \mathrm{~Hz}$ with amplitude 1.5 and another at $8.40 \mathrm{~Hz}$ with amplitude 1.5. So, in the case of an earthquake, seismic components that will be amplified on the total of those generated by the earthquake will be those from 2.5$3 \mathrm{~Hz}$ that will be amplified by a factor of approximately 3.5 and those at $5.5 \mathrm{~Hz}$ by a factor of 1.5 times. Other frequencies are high compared to the terms of those generated by an earthquake so are irrelevant in the case of an earthquake (Fig. 3).

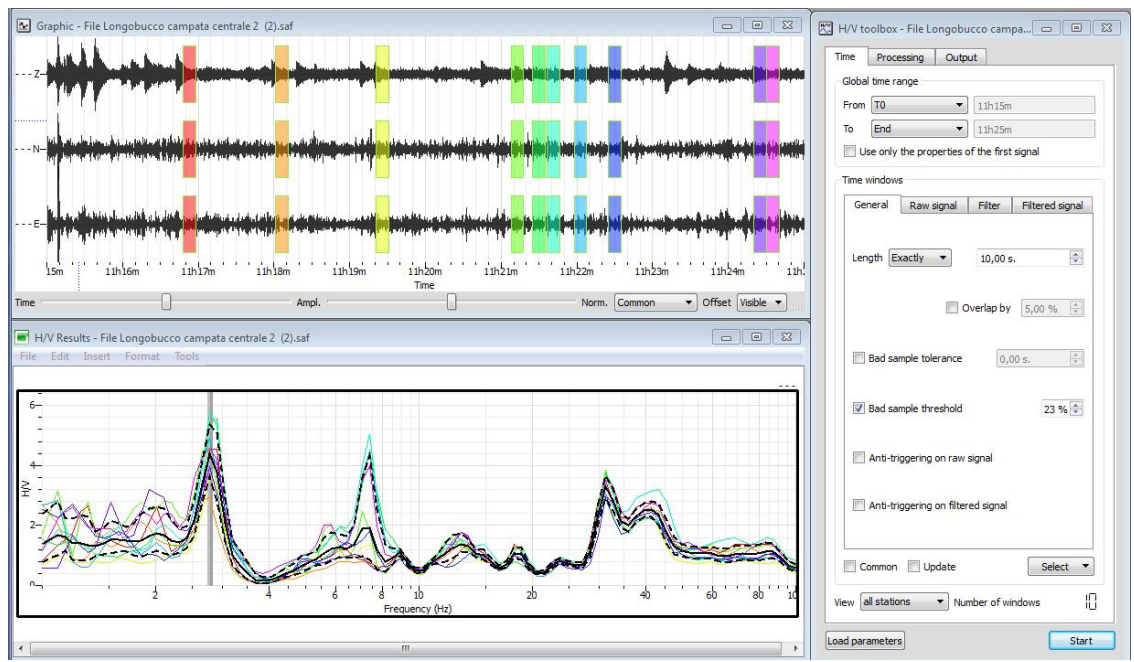

Figure 3: Graphic data processing carried out with passive seismic tomograph. 
In the preliminary experimental phase, we proceeded with the identification of significant points at which to place eight seismic accelerometers and obtain an adequate level of information for the reconstruction of the vibration behavior of the bridge. The methodology used for the dynamic characterization consists in detecting accelerations induced by wind and traffic. This was simulated by having a single vehicle pass across the bridge. All measurements were made in the central section in correspondence to the arch of the bridge. In the preliminary phase of the experiment, we proceeded to the identification of significant points of where to place eight seismic accelerometers and obtain an adequate level of information for the reconstruction of the vibration behavior of the bridge.

The data obtained from the accelerometers give the following results (shown in Fig. 4).

\begin{tabular}{|c|c|c|c|c|c|c|c|c|}
\hline TEST & $1 \%$ Pesd & $z^{2}$ Pesd: & 3Pesck & 44 pesd & 5\%pesd: & 6 Pesch & TPesd: & 8Pesd \\
\hline 1 & 2.8 & 3.66 & 5.005 & 6.22 & 7.751 & 8.48 & & 9.52 \\
\hline 2 & 2.8 & 3.54 & 5.005 & 6.22 & 7.81 & 8.42 & & 9.52 \\
\hline 3 & 2.8 & 3.54 & 5.066 & 6.22 & 7.87 & 8.42 & 9.27 & 9.58 \\
\hline 4 & 2.8 & 3.66 & 5.005 & 6.22 & 7.93 & 8.3 & 9.27 & 9.64 \\
\hline 5 & 2.8 & 3.47 & 5.127 & 6.22 & 7.81 & 8.54 & 9.27 & 9.64 \\
\hline 6 & 2.8 & 3.54 & 5.005 & 6.104 & 7.87 & 8.36 & 9.27 & 9.64 \\
\hline 7 & 2.8 & 3.66 & 5.066 & & 7.81 & 8.6 & 9.21 & 9.64 \\
\hline 8 & 2.8 & 3.54 & & & 7.81 & & 9.33 & \\
\hline
\end{tabular}

Figure 4: Accelerometric data.

It can be seen that the peaks found using the accelerometer are in clear correspondence with the peaks found using the passive seismic procedure performed using an experimental tomograph.

The results obtained show that the artifact under investigation still retains the dynamic characteristics of the project because the frequencies calculated experimentally coincide with those obtained using the seismic accelerometer.

\section{Conclusion}

The objective was to "detect" the dynamic behavior of a structure as an effect of the shaking induced by seismic noise or environmental micro-tremors.

By means of this mechanism, we expected that the energy transfer from the ground to the artefact through its foundations makes it possible to evaluate damage undergone by a building due to seismic activity. It is evident that the most suitable method in the diagnosis of structural damage consists of comparing a numerical model with the real structure and also researching into eventual identified discrepancies.

The problem is usually addressed following a linear progression that goes from the definition seismic motion on the ground (seismological aspect) to the subsequent estimation of the response of the structure subjected to the stress (engineering part). 
In the engineering analysis, and also in the technical regulation, the emphasis is on the individual structure and its vulnerability.

In effect, an earthquake strikes the system of facilities and infrastructure on a "territorial" scale (municipalities, provinces, regions). Prevention policies, emergency management and policies of land use planning, to be effective, must therefore operate on this larger scale. To this purpose, the high level knowledge of the degree of vulnerability of the structures is totally inadequate for the establishment of effective intervention policies.

There is a strong demand for innovative techniques which can be used extensively for the evaluation of greater numbers of structures in order to ensure a prevention policy which is both aware and effective.

The answer to this kind of need is to be sought in the development of low-cost investigation techniques, capable of providing adequate results, even if not exhaustive, and which are at least useful in identifying the most critical situations to be addressed with the most urgency.

If the soil-structure resonances coincide, the situation is unfavorable from the point of view of seismic vulnerability. Further, the situation is also unfavourable if the resonance frequencies of the structure are slightly greater than those of the subsoil because:

a) the resonant frequency of buildings and/or structures diminishes over time;

b) the subsoil can manifest vibration behaviours of greater amplitude and of a frequency greater than that seen with microtremors.

So it is appropriate that the resonance frequency of the structure always be different the resonance peak of the ground, especially if this latter is very pronounced.

The instrumentation must be sufficiently sensitive to record the microtremors present in the soil.

\section{References}

[1] Amato, A., B. Alessandrini, G. B. Cimini, A. Frepoli, and G. Selvaggi, Active and remnant subducted slabs beneath Italy: Evidence from seismic tomography and seismicity, Ann. Geofis., 36, 201-214, 1993.

[2] Bard P.-Y., 1998. Microtremor measurements: a tool for site effect estimation? Second International Symposium on the Effects of the Surface Geology on Seismic Motion-ESG98, Japan.

[3] Chavez-Garcia F. J., Rodriguez M. and Stephenson R., 2006. Subsoil structure using SPAC measurements along a line, Bull. Seismol. Soc. Am., 96 (2), 729-736.

[4] D’Amico V., Picozzi M., Albarello D., Naso G. and Tropenscovino S., 2004. Quick estimates of soft sediment thicknesses from ambient noise horizontal to vertical spectral ratios: a case study in southern Italy, J. Earthq. Eng., 8, 895-908.

[5] D’Amico V., Albarello D., Baliva F., Picozzi M. and Agili F., 2006. Site response characterization of the Florence urban area (Italy) using seismic 
noise measurements. 1st European Conference on Earthquake Engineering and Seismology, Geneva, Switzerland, Abstract Book, 333.

[6] Delgado J., Lopez Casado C., Giner J., Estevez A., Cuenca A. and Molina, S., 2000. Microtremors as a geophysical exploration tool: applications and limitations, Pure Appl. Geophys., 157, 1445-1462.

[7] Delgado J., Lopez Casado C., Giner J., Estevez A., Cuenca A., Molina S., 2000a. Microtremors as a geophysical exploration tool: applications and limitations, Pure Appl. Geophys., 157, 1445-1462.

[8] Gallipoli R., La Penna V., Lorenzo P. et al., 2000. Comparison of geological and geophysical prospecting techniques in the study of a landslide in southern Italy, European J. Environm. and Eng. Geophys., 4, 117-128.

[9] Critelli, S., 1999, The interplay of lithospheric flexure and thrust accommodation in forming stratigraphic sequences in the Southern Apennines foreland basin system, Italy: Academia Nazionale de Lincei, Rendiconti Lincei Scienze Fisiche e Naturali, serie IX, v. 10, pp. 257-326.

[10] Hinzen K.-G., Scherbaum F., Weber B., 2004. On the resolution of H/V measurements to determine sediment thickness, a case study across a normal fault in the Lower Rhine embayment, Germany, J. Earthq. Eng., 8, 909-926.

[11] Monachesi, G., and M. Stucchi, DOM 4.1 an intensity database of damaging earthquakes in the Italian area, 1998. (Available as http://emidius.itim.mi.cnr.it/DOM/home.html).

[12] Nakamura Y., 1989. A method for dynamic characteristics estimates of subsurface using microtremor on the round surface, $Q R$ of RTRI, 30, 25-33.

[13] Nogoshi M. and Igarashi T., 1970. On the propagation characteristics of microtremors, J. Seism. Soc. Japan, 23, 264-280.

[14] Mucciarelli M. and Gallipoli M.R., 2001. A critical review of 10 years of microtremor HVSR technique, Bollettino di Geofisica Teoria ed Applicata, 42, 255-266.

[15] Mucciarelli M. and Gallipoli M.R., 2006. Comparison between Vs30 and other estimates of site amplification in Italy, Conf. Eartq. Eng. and Seismol., Geneva, 3-8 Sept. 2006, no. 270.

[16] SESAME, 2005. http://sesame-fp5.obs.ujf-grenoble.fr/index.htm 